\title{
Research perspectives in the etiology of congenital anorectal malformations using data of the International Consortium on Anorectal Malformations: evidence for risk factors across different populations
}

\author{
Charlotte H. W. Wijers - Ivo de Blaauw - Carlo L. M. Marcelis - Rene M. H. Wijnen • Han Brunner • \\ Paola Midrio • Piergiorgio Gamba • Maurizio Clementi • Ekkehart Jenetzky • Nadine Zwink • Heiko Reutter • \\ Enrika Bartels • Sabine Grasshoff-Derr • Stefan Holland-Cunz • Stuart Hosie • Stefanie Märzheuser • \\ Eberhard Schmiedeke • Célia Crétolle • Sabine Sarnacki • Marc A. Levitt • Nine V. A. M. Knoers • \\ Nel Roeleveld • Iris A. L. M. van Rooij \\ Published online: 21 August 2010 \\ (C) The Author(s) 2010. This article is published with open access at Springerlink.com
}

\begin{abstract}
Purpose The recently established International Consortium on Anorectal Malformations aims to identify genetic and environmental risk factors in the etiology of syndromic and nonsyndromic anorectal malformations (ARM) by
\end{abstract}

C. H. W. Wijers $(\bowtie) \cdot$ N. Roeleveld · I. A. L. M. van Rooij Department of Epidemiology, Biostatistics and HTA (133), Radboud University Nijmegen Medical Centre, P.O. box 9101, 6500 HB Nijmegen, The Netherlands

e-mail: L.Wijers@ebh.umcn.nl

I. de Blaauw · R. M. H. Wijnen - M. A. Levitt

Department of Pediatric Surgery,

Erasmus Medical Centre-Sophia Children's Hospital,

Rotterdam, The Netherlands

C. L. M. Marcelis - H. Brunner - N. V. A. M. Knoers

Department of Human Genetics, Radboud University Nijmegen

Medical Centre, Nijmegen, The Netherlands

P. Midrio · P. Gamba

Department of Pediatric Surgery, University of Padua, Padua, Italy

\section{Clementi}

Clinical Genetics Service, Department of Pediatrics,

University of Padua, Padua, Italy

E. Jenetzky $\cdot$ N. Zwink

Division of Clinical Epidemiology and Aging Research, German

Cancer Research Centre, Heidelberg, Germany

H. Reutter · E. Bartels

Institute of Human Genetics, University of Bonn, Bonn,

Germany

H. Reutter

Department of Neonatology, Children's Hospital,

University of Bonn, Bonn, Germany promoting collaboration through data sharing and combined research activities.

Methods The consortium attempts to recruit at least 1,000 ARM cases. DNA samples are collected from case-parent triads to identify genetic factors involved in ARM. Several

\section{S. Grasshoff-Derr}

Department of Pediatric Surgery, University Hospital Würzburg, Würzburg, Germany

S. Holland-Cunz

Department of Pediatric Surgery, University of Heidelberg, Heidelberg, Germany

\section{S. Hosie}

Department of Pediatric Surgery, Klinikum Schwabing,

Technical University Munich, Munich, Germany

\section{S. Märzheuser}

Department of Pediatric Surgery,

Charité Universitätsmedizin Berlin,

Berlin, Germany

\section{E. Schmiedeke}

Department of Pediatric Surgery and Urology,

Centre for Child and Youth Health, Klinikum Bremen-Mitte,

Bremen, Germany

C. Crétolle $\cdot$ S. Sarnacki

Department of Pediatric Surgery, National Reference Center for Rare Disease on Anorectal Malformations and Rare Pelvic Anomalies (MAREP),

Paris, France

M. A. Levitt

Colorectal Center for Children, Cincinnati Children's Hospital Medical Center, Cincinnati, USA 
genetic techniques will be applied, including SNP arrays, gene and whole exome sequencing, and a genome-wide association study. Questionnaires inquiring about circumstances before and during pregnancy will be used to obtain environmental risk factor data.

Results Currently, 701 ARM cases have been recruited throughout Europe. Clinical data are available from all cases, and DNA samples and questionnaire data mainly from the Dutch and German cases. Preliminary analyses on environmental risk factors in the Dutch and German cohort found associations between ARM and family history of ARM, fever during first trimester of pregnancy and maternal job exposure to cleaning agents and solvents.

Conclusion First results show that both genetic and environmental factors may contribute to the multifactorial etiology of ARM. The International Consortium on Anorectal Malformations will provide possibilities to study and detect important genes and environmental risk factors for ARM, ultimately resulting in better genetic counseling, improved therapies, and primary prevention.

Keywords Anorectal malformation - Genetics ·

Environmental factors · Etiology · Children · Birth defects

\section{Introduction}

Congenital anorectal malformations (ARM) are rare disorders, occurring in approximately 1 in 5,000 to 1 in 1,500 live births worldwide [1]. These disorders usually require surgical interventions in the neonatal period and postoperative follow-up and treatment to obtain and maintain fecal and urinary continence. Sequelae of ARM continue into adulthood and may include fecal incontinence and sexual dysfunction. All these issues cause major concerns for parents and children at school age and in later life, and pose a large social problem connected with acceptance of the population suffering from these problems. Clinical outcomes of ARM, such as functional stooling problems, are found to be directly associated with poor quality of life in ARM patients [2,3]. These outcomes often deteriorate with age, which emphasizes the need for long-term follow-up and psychosocial treatment $[2,3]$. As experience concerning ARM is scattered in many different hospitals in most European countries [4], regional differences in clinical outcome and quality of life have been reported. Moreover, case comparison is difficult, as a detailed diagnosis according to Krickenbeck [5] is often not stated in discharge letters.

Despite the great physical and social burden on ARM patients and their parents, the etiology is largely unknown. In rare cases, ARM can be explained by chromosomal abnormalities or is part of a well-known syndrome. Townes-Brocks syndrome, comprising ear, limb, anal, renal, and heart anomalies, is caused by mutations in the SALL1 gene [6,7], whereas mutations in the homeobox gene HLXB9 lead to
Currarino syndrome, a combination of sacral agenesis, presacral mass, and ARM [8-10]. However, clinical manifestations of syndromic forms of ARM may vary and genetics and underlying mechanisms remain elusive. The majority of ARM cases are not part of a syndrome and their etiology is assumed to be multifactorial with a causal interplay of genetic and environmental factors. Evidence for genetic factors involved in the anorectal development is mainly derived from syndromic ARM and animal studies rather than from studies on nonsyndromic ARM. In addition to genetic factors, an essential role is expected for environmental factors as ARM rarely aggregates in families [11]. Some researchers studied environmental hazards and found associations between ARM and maternal alcohol intake [12], tobacco smoke, and caffeine [13], the benzodiazepine lorazepam [14], paternal exposure to occupational hazards $[15,16]$, and folic acid supplementation [17]. In addition to these factors, increased risks were found after in vitro fertilization [18-20]. However, strong evidence is still scarce as most potential risk factors were found in only one study and the majority of the studies had low power.

To summarize, large scale studies on genetic and environmental risk factors with human ARM cases have not yet been performed, but could provide substantial clues on the pathogenesis of ARM. ARM would benefit from prevention, accurate diagnosis, and outlined clinical treatment. Clinical research on regional differences in clinical outcome and quality of life may contribute to improvements in patient care. Recently, the International Consortium on Anorectal Malformations, consisting of the Dutch AGORA project (Aetiologic research into Genetic, Occupational and environmental Risk factors for Anomalies in children), the German CURE-Net (German Network for Congenital UroREctal Malformations), the Italian MUGAR-Net (Network for Uro-Genito-Ano-Rectal malformations in Italy), and the French MAREP (National Center for AnoRectal Malformations and rare Pelvic Anomalies), has been established for etiologic and clinical research. Our multidisciplinary consortium of geneticists, epidemiologists, and clinician-scientists strongly believes that a fundamental prerequisite for progress in the field of rare developmental disorders, such as ARM, will be to strengthen the ties between clinical and basic research activities. In this report, our mission and specific research goals regarding the pathobiology of ARM will be addressed. In addition, the first results on environmental risk factors from the Dutch and German ARM cohort will be presented.

\section{Methods}

Consortium on Anorectal Malformations

Researchers from the participating countries initiated the establishment of an International Consortium on Anorectal 
Malformations. Our common goal is to collaborate and exchange knowledge on a research topic that is still in its infancy. We aim to perform high quality etiologic research on ARM and to standardize diagnostic classifications and clinical outcomes of ARM patients throughout Europe. The consortium will create a registry of ARM patients, which will serve as a base for all research on ARM. This registry is essential for etiologic research, which needs adequately registered diagnoses of ARM patients, as different phenotypes of ARM may originate from different pathogenic processes.

At the current stage of research, more and more emphasis is placed on large numbers of patients and development of biobanks for both rare and frequently occurring disorders. Therefore, the participants in this consortium consider it of utmost importance to collect a critical mass of clinical data and biomaterials from children affected by ARM and their parents in a collaborative effort. The international collaboration will create case series of patients with data and biomaterials that would be hard to achieve on a national scale in any country. We aim to recruit at least 1,000 ARM cases within the countries participating in the consortium. Blood or saliva samples are collected from case-parent triads for genetic analyses. Questionnaires inquiring about circumstances 3 months before and during pregnancy will be used to obtain environmental risk factor data from the parents. Potential environmental risk factors are those that are capable of affecting the formation of oocytes and spermatozoa and/or may influence the development of the embryo. A special database for questionnaire and clinical data will be set up that can be used for data entry in all participating countries. Professional data management will facilitate ongoing clinical collaborative projects ensuring data quality and compatibility. The following paragraphs describe the existing projects of patient and data collection in the currently participating countries of the consortium.

\section{AGORA, The Netherlands}

The AGORA project (Aetiologic research on Genetic, Occupational and environmental Risk factors for Anomalies in children) was started at the Radboud University Nijmegen Medical Centre (RUNMC), Nijmegen, The Netherlands in 2005. Several disciplines collaborate in AGORA, namely genetic, epidemiologic, and pediatric departments, with the common aim to study the role of genetic and environmental risk factors in the etiology of a variety of congenital malformations, including ARM. Blood or saliva samples and environmental data are routinely collected from case-parent triads during diagnostic or surgical procedures. The ideal control group, which consists of a random sample of the Dutch population in the relevant age group, will also be recruited to perform research on all congenital malformation patient groups within AGORA.

\section{CURE-Net, Germany}

The German Network for Congenital Uro-REctal Malformations (CURE-Net) represents the first systematic approach in Germany to investigate the molecular causes of congenital uro-rectal malformations, employing an integrated network structure that involves basic research disciplines, and to establish the first prospective multicenter study into the clinical implications and psychosocial outcome of these disorders. CURE-Net was founded in 2008 with federal funding by the German Federal Ministry of Education and Research (BMBF) starting in 2009. To ensure efficient recruitment of patients and their families, central recruitment has been established with all participating families being assessed in person by one of four physicians specialized in clinical genetics and/or pediatric surgery. DNA samples of each participating individual are stored in a central DNA biomaterial bank. The phenotypic information is documented in a nationwide register.

\section{MUGAR-Net, Italy}

The MUGAR-Net project (Network for Uro-Genito-AnoRectal malformations in Italy) is an ongoing project that does not exist in Italy at the moment, which aims to set up an Italian registry for urogenital and anorectal malformations. The registry will allow us to perform epidemiological studies, make health-care workers aware of the problem, collect blood and saliva samples from affected patients in a biobank, and finally establish cooperation with other international centers.

\section{MAREP, France}

The national center for AnoRectal Malformations and rare Pelvic anomalies (MAREP) was created in 2007 as part of the National French Program for Rare Disease (2005-2008). Its main objectives are to develop a French registry gathering anatomical and clinical data, to edit guidelines for the optimal management and follow-up of patients with ARM, and to diffuse information to patients, families, and medical actors to ensure equality for diagnostics, treatment, and care. Genetic diseases screening, research development and European collaborations form a large part of our missions as well. Data are collected and recorded online in a database called CEMARA (for CEntre MAladies RAres), which interacts with the Orphanet database. Blood samples are already collected in syndromic 
forms and collection will be extended to all enrolled patients. This center is also the national referent for Currarino syndrome molecular sequencing, and 90 index cases have been recorded. MAREP currently collects about 50-60 new ARM cases per year and is thus ready to participate in the consortium.

\section{Research possibilities}

The substantial amount of data that will be obtained within the consortium offers many possibilities for ARM research. Due to rapid developments in the genetic field, existing techniques in performing genetic research have also changed rapidly. SNP arrays and new promising gene sequencing techniques are appropriate in performing research regarding syndromic forms of ARM. Identification of genes mediating syndromic forms of ARM may also provide suggestions for the role of genetic factors in the etiology of more isolated forms of ARM. At the current stage, however, indications for specific candidate genes involved in the more isolated forms of ARM are nearly absent. Therefore, hypothesis-free research on nonsyndromic ARM seems to be most appropriate. We intend to perform a genome-wide association study (GWAS) in a large cohort of more isolated nonsyndromic ARM cases. In this hypothesis-generating approach, the whole genome will be scanned to identify potential SNPs involved in nonsyndromic ARM. To identify specific environmental risk factors, questionnaire data will be investigated. Since this will be a unique and relatively large cohort of ARM cases, identification of environmental risk factors seems likely. In a GWAS with 1,000 cases and controls and assuming $80 \%$ power, main genetic effects of $\geq 1.5$ can be identified for genes with an allele frequency $>0.05$. For environmental factors with an exposure prevalence of 0.1 , main effects $\geq 1.5$ can also be detected.

Dutch and German studies on environmental risk factors

In our first Dutch case-control study among 85 nonsyndromic ARM cases and 650 controls, potential environmental risk factors for ARM were studied [21]. ARM cases with chromosomal anomalies, known syndromes, cloaca, and cloacal extrophies were excluded. Parents of these cases and controls filled out questionnaires, concerning exposures just before and during pregnancy. Recently, we tried to replicate the findings of the Dutch case-control study in 79 nonsyndromic ARM cases from the German CURE-Net. Due to the close geographic proximity and the assumed analogy in ethnicity, controls were used from the Dutch case-control study. Dutch and German questionnaires were nearly similar with regard to the environmental risk factors studied, apart from time to pregnancy (TTP), which was only included in the Dutch questionnaire.

\section{Results}

Data collection within the International Consortium on Anorectal Malformations

A relatively large amount of data has already been collected in Europe during the past few years. Currently, approximately 700 ARM cases have been recruited: 275 cases in the Netherlands, 172 in Germany, 140 in Italy, and 114 cases in France. Clinical data are available for all these cases. The members of the consortium are currently harmonizing their case reports to combine these data. As Italy and France had just started data collection, DNA samples and questionnaire data were mainly collected from ARM cases in the Netherlands and Germany (Table 1). Some other potential (non-)European collaborators may also contribute data to increase the total number of ARM cases in the future.

\section{Results of Dutch case-control study}

In our Dutch case-control study among 85 nonsyndromic ARM cases, we found associations between ARM and family history of ARM, time to pregnancy $>6$ months, prepregnancy BMI $\geq 25 \mathrm{~kg} / \mathrm{m}^{2}$, fever during first trimester of pregnancy, maternal job exposure to industrial cleaning agents and solvents, paternal smoking, and paternal job exposures to exhaust fumes [21] (Table 2).
Table 1 Collected data of ARM cases per country

* Partial questionnaire data,

\# Minimum

\begin{tabular}{lllll}
\hline & \multicolumn{2}{l}{ Number of collected data of ARM cases } & \multirow{2}{l}{$\begin{array}{l}\text { Intention to } \\
\text { collect in total }\end{array}$} \\
\cline { 2 - 4 } & $\begin{array}{l}\text { Clinical } \\
\text { data }\end{array}$ & $\begin{array}{l}\text { DNA } \\
\text { samples }\end{array}$ & $\begin{array}{l}\text { Environmental } \\
\text { data }\end{array}$ & \\
\hline Netherlands (AGORA) & 275 & 275 & 220 & 300 \\
Germany (CURE-Net) & 172 & 131 & 156 & 300 \\
Italy (MUGAR-Net) & 140 & 20 & 10 & 200 \\
France (MAREP) & 114 & 50 & $114^{*}$ & 200 \\
Total & 701 & 476 & 500 & 1,000 \\
\hline
\end{tabular}


Table 2 Summary of results of our Dutch case-control study on risk factors of ARM [23]

\begin{tabular}{|c|c|c|c|}
\hline Potential risk factors & $\begin{array}{l}\operatorname{ARM}(n=85) \\
n(\%)\end{array}$ & $\begin{array}{l}\text { Controls }(n=650) \\
n(\%)\end{array}$ & $\mathrm{OR}_{\text {adjusted }}(95 \% \mathrm{CI})$ \\
\hline Family history of ARM first and second degree & $6(7.2)$ & $1(0.2)$ & $33.9(2.9-398)$ \\
\hline Time to pregnancy $>6$ months & $26(32.9)$ & $135(21.4)$ & $1.8(1.1-3.0)$ \\
\hline \multicolumn{4}{|l|}{ Maternal risk factors } \\
\hline BMI before pregnancy $\geq 25 \mathrm{~kg} / \mathrm{m}^{2}$ & $32(38.1)$ & $160(26.0)$ & $1.8(1.1-2.8)$ \\
\hline Fever first trimester pregnancy $\left(>38^{\circ} \mathrm{C}\right)$ & $3(3.7)$ & $4(0.6)$ & $5.1(0.9-28.1)$ \\
\hline Maternal job exposure to industrial cleaning agents and solvents & $5(6.0)$ & $12(1.9)$ & $2.9(0.9-9.3)$ \\
\hline \multicolumn{4}{|l|}{ Paternal risk factors ( 3 months prior to conception) } \\
\hline Paternal smoking of cigarettes & $41(50.0)$ & $210(35.7)$ & $1.8(1.1-2.9)$ \\
\hline Paternal job exposure to exhaust fumes & $14(17.3)$ & $59(10.0)$ & $1.9(1.0-3.6)$ \\
\hline
\end{tabular}

Results derived from the article in Birth Defects Research (Part A) [23]

Table 3 Replication of results on environmental risk factors for ARM using German ARM cases

\begin{tabular}{|c|c|c|c|}
\hline Potential risk factors & $\begin{array}{l}\text { German ARM } \\
(n=79) \\
n(\%)\end{array}$ & $\begin{array}{l}\text { Dutch controls } \\
(n=650) \\
n(\%)\end{array}$ & $\begin{array}{l}\mathrm{OR}_{\text {crude }} \\
(95 \% \mathrm{CI})\end{array}$ \\
\hline Family history of ARM first and second degree & $6(7.6)$ & $1(0.2)$ & $49.0(5.8-412.6)$ \\
\hline \multicolumn{4}{|l|}{ Maternal risk factors } \\
\hline BMI before pregnancy $\geq 25 \mathrm{~kg} / \mathrm{m}^{2}$ & $20(25.3)$ & $160(26.0)$ & $1.0(0.6-1.7)$ \\
\hline Fever first trimester pregnancy $\left(>38^{\circ} \mathrm{C}\right)$ & $5(6.3)$ & $4(0.6)$ & $10.6(2.8-40.4)$ \\
\hline Maternal job exposure to industrial cleaning agents and solvents & $10(12.7)$ & $12(1.9)$ & $7.4(3.1-17.7)$ \\
\hline \multicolumn{4}{|l|}{ Paternal risk factors ( 3 months prior to conception) } \\
\hline Paternal smoking of cigarettes & $28(35.4)$ & $210(35.7)$ & $1.0(0.6-1.6)$ \\
\hline Paternal job exposure to exhaust fumes & $4(5.1)$ & $59(10.0)$ & $0.5(0.2-1.4)$ \\
\hline
\end{tabular}

Preliminary results of the German CURE-Net

The Dutch results were reanalyzed with 79 ARM cases of the German CURE-Net study. These cases were classified according to Krickenbeck [5]. The most frequently occurring diagnoses were perineal fistula (total 19.0\%; $9.3 \%$ in boys and $30.5 \%$ in girls), vestibular fistula in girls $(36.1 \%)$, and rectourethral fistula in boys $(51.1 \%)$. The preliminary results showed associations between ARM and family history of ARM, fever during first trimester of pregnancy, and maternal job exposure to industrial cleaning agents and solvents (Table 3). No associations were found between ARM and BMI before pregnancy of $\geq 25 \mathrm{~kg} / \mathrm{m}^{2}$, paternal smoking, and paternal job exposure to exhaust fumes. These results were not adjusted for confounders.

\section{Discussion}

The replication of the Dutch results using the German CURE-Net data shows the added value of our International Consortium. Interestingly, associations between ARM and family history of ARM, fever during first trimester of pregnancy, and maternal job exposure to industrial cleaning agents and solvents could be replicated in the German cohort of ARM cases. Family history of ARM has consistently been identified as a risk factor for ARM [22], which argues for the importance of genetic factors involved in ARM. Maternal fever during first trimester of pregnancy was indicated as a potential risk factor for ARM in the Dutch case-control study for the first time. As this association was replicated in the German cohort, it seems extremely worthwhile to further study this potential risk factor in detail. It may be essential to incorporate maternal fever, maternal infections, and antifebrile treatment in the consortium's questionnaire on environmental risk factors to explore the underlying mechanism of the association between ARM and fever. In previous studies and in the Dutch and German cohorts, some job exposures were found to be associated with ARM, such as organic solvents and metals $[15,16]$. As it remains questionable whether the rather crude assessment of parental exposure to occupational agents reflects real exposure, we intend to analyze these occupational exposures in a more accurate way and in a larger cohort of ARM patients. Although the Dutch casecontrol study [21] and previous studies [23, 24] found an 
association between ARM and BMI before pregnancy $\geq 25 \mathrm{~kg} / \mathrm{m}^{2}$, it could not be confirmed in the German study. Associations between ARM and paternal smoking and paternal job exposure to exhaust fumes were not replicated in the German cohort either. These preliminary results have some limitations, which should also be considered. In the German analyses, the control group of the Dutch casecontrol study was used. Although we expect that the Dutch and German population correspond for the most part with regard to social standards and lifestyle factors, some geographical differences may exist. In the future, we intend to recruit controls in all participating countries to achieve true geographical similarity between cases and controls. In addition, the small sample sizes of the two case series made it difficult to provide reliable findings for less frequently occurring risk factors. However, these findings encourage us to reanalyze the current findings in a larger international study population, in which other interesting environmental risk factors may be found as well.

\section{Conclusion}

The recently established International Consortium on Anorectal Malformations, uniting researchers from the Netherlands, Germany, Italy, and France, will collect a large amount of data available for ARM research. The ensuing large cohort of ARM cases will provide possibilities to study and detect important genes and environmental risk factors involved in the etiology of syndromic and nonsyndromic forms of ARM, finally combining these to identify gene-environment interaction as well. Consequently, it is expected that the etiology of ARM will gradually be unraveled in the future, which will also provide a substantial amount of information on the pathogenesis of ARM. This knowledge may result in better genetic counseling, perinatal care, and ultimately primary prevention of ARM. While the current research focus is on finding causative factors, clinical issues will also become important. The consortium brings together pediatric surgeons to harmonize diagnostic classifications, interventions, and follow-up and to improve quality of life of ARM patients. In the future, other international pediatric surgery, and genetic or epidemiological research groups may be involved in the consortium.

Acknowledgments The authors thank the patients and their parents for their participation in the study. The authors are grateful to the staff of the Departments of Pediatric Surgery and Otorhinolaryngology of the Radboud University Nijmegen Medical Centre. The authors also thank the German support group for people with congenital anorectal malformations (SoMA e.V.) for their kind support in contacting patients and Peter Reifferscheid for design of the German patient questionnaire and his critical comments on the evaluation of clinical data. The authors are also grateful to Dalia Aminoff, President of the Italian Association of Anorectal Malformation (AIMAR). CW is supported by a grant from the Radboud University Nijmegen Medical Centre. EJ, NZ, HR, EB, SG-D, SH-C, SH, SM, and ES are members of the "Network for Systematic Investigation of the Molecular Causes, Clinical Implications and Psychosocial Outcome of Congenital Uro-Rectal Malformations (CURE-Net)" supported by a research grant (01GM08107) from the German Federal Ministry of Education and Research (Bundesministerium für Bildung und Forschung, BMBF): http://www.cure-net.de.

Open Access This article is distributed under the terms of the Creative Commons Attribution Noncommercial License which permits any noncommercial use, distribution, and reproduction in any medium, provided the original author(s) and source are credited.

\section{References}

1. International Clearinghouse Birth Defects Surveillance and Research. Annual Report 2008, with data for 2006

2. Hashish MS, Dawoud HH, Hirschl RB, Bruch SW, El Batarny AM, Mychaliska GB, Drongowski RA, Ehrlich PF, Hassaballa SZ, El-Dosuky NI, Teitelbaum DH (2010) Long-term functional outcome and quality of life in patients with high imperforate anus. J Pediatr Surg 45:224-230

3. Hartman EE, Oort FJ, Visser MR, Sprangers MA, Hanneman MJ, de Langen ZJ, va Heurn LW, Rieu PN, Madern GC, van der Zee DC, Looyard N, van Silfhout-Bezemer M, Aronson DC (2006) Explaining change over time in quality of life of adult patients with anorectal malformations or Hirschsprung's disease. Dis Colon Rectum 49:96-103

4. Jenetzky E (2007) Prevalence estimation of anorectal malformations using German diagnosis related groups system. Pediatr Surg Int 23:1161-1165

5. Holschneider A, Hutson J, Peña A, Beket E, Chatterjee S, Coran A, Davies M, Georgeson K, Grosfeld J, Gupta D, Iwai N, Kluth D, Martucciello G, Moore S, Rintala R, Smith ED, Sripathi DV, Stephens D, Sen S, Ure B, Grasshoff S, Boemers T, Murphy F, Söylet Y, Dübbers M, Kunst M (2005) Preliminary report on the International Conference for the Development of Standards for the Treatment of Anorectal Malformations. J Pediatr Surg 40: $1521-1526$

6. Kohlhase J, Wischermann A, Reichenbach H, Froster U, Engel W (1998) Mutations in the SALL1 putative transcription factor gene cause Townes-Brocks syndrome. Nat Genet 18:81-83

7. Liang Y, Shen D, Cai W (2008) Two coding single nucleotide polymorphisms in the SALL1gene in Townes-Brocks syndrome: a case report and review of the literature. J Pediatr Surg 43:391-393

8. Belloni E, Martucciello G, Verderio D, Ponti E, Seri M, Jasonni V, Torre M, Ferrari M, Tsui LC, Scherer SW (2000) Involvement of the HLXB9 homeobox gene in Currarino syndrome. Am J Hum Genet 66:312-319

9. Hagan DM, Ross AJ, Strachan T, Lynch SA, Ruiz-Perez V, Wang YM, Scambler P, Custard E, Reardon W, Hassan S, Muenke M, Nixon P, Papapetrou C, Winter RM, Edwards Y, Morrison K, Barrow M, Cordier-Alex M, Correia P, Galvin-Parton PA, Gaskill S, Gaskin KJ, Garcia-Minaur S, Gereige R, Hayward R, Homfray T, McKeown C, Murday V, Plauchu H, Shannon N, Spitz L, Lindsay S (2000) Mutation analysis and embryonic expression of the HLXB9 Currarino syndrome gene. Am J Hum Genet 66:1504-1515

10. Crétolle C, Pelet A, Sanlaville D, Zérah M, Amiel J, Jaubert F, Révillon Y, Baala L, Munnich A, Nihoul-Fékété C, Lyonnet S 
(2008) Spectrum of HLXB9 gene mutations in Currarino syndrome and genotype-phenotype correlation. Hum Mutat 29:903-910

11. Landau D, Mordechiai J, Karplus M, Carmi R (1997) Inheritance of familial congenital isolated anorectal malformations: case report and review. Am J Med Genet 71:280-282

12. Yuan P, Okazaki I, Kuroki Y (1995) Anal atresia: effect of smoking and drinking habits during pregnancy. J Hum Genet 40:327-332

13. Miller EA, Manning SE, Rasmussen SA, Reefhuis J, Honein MA, National Birth Defects Prevention Study (2009) Maternal exposure to tobacco smoke, alcohol and caffeine, and risk of anorectal atresia: National Birth Defects Prevention Study 1997-2003. Paediatr Perinat Epidemiol 23:9-17

14. Bonnot O, Vollset SE, Godet PF, D'Amato T, Robert E (2001) Maternal exposure to lorazepam and anal atresia in newborns: results from a hypothesis-generating study of benzodiazepines and malformations. J Clin Psychopharmacol 21:456-458

15. Stoll C, Alembik Y, Roth MP, Dott B (1997) Risk factors in congenital anal atresias. Ann Genet 40:197-204

16. Schnitzer PG, Olshan AF, Erickson JD (1995) Paternal occupation and risk of birth defects in offspring. Epidemiology 6:577-583

17. Myers MF, Li S, Correa-Villaseñor A, Li Z, Moore CA, Hong SX, Berry RJ, China-US Collaborative Project for Neural Tube Defect Prevention (2001) Folic acid supplementation and risk for imperforate anus in China. Am J Epidemiol 154:1051-1056
18. Källén B, Finnström O, Nygren KG, Olausson PO (2005) In vitro fertilization (IVF) in Sweden: risk for congenital malformations after different IVF methods. Birth Defects Res (Part A) 73:162-169

19. Reefhuis J, Honein MA, Schieve LA et al (2008) Assisted reproductive technology and major structural birth defects in the United States. Hum Reprod 24:360-366

20. Midrio P, Nogare CD, Di Gianantonio E, Clementi M (2006) Are congenital anorectal malformations more frequent in newborns conceived with assisted reproductive techniques? Reprod Toxicol 22:576-577

21. van Rooij IA, Wijers CH, Rieu PN, Hendriks HS, Brouwers MM, Knoers NV, de Blaauw I, Roeleveld N (2010) Maternal and paternal risk factors for anorectal malformations: a Dutch casecontrol study. Birth Defects Res A Clin Mol Teratol 88:152-158

22. Falcone RA Jr, Levitt MA, Peña A, Bates M (2007) Increased heritability of certain types of anorectal malformations. J Pediatr Surg 42:124-128

23. Blomberg MI, Källén B (2010) Maternal obesity and morbid obesity: the risk for birth defects in the offspring. Birth Defects Res A Clin Mol Teratol 88:35-40

24. Waller DK, Shaw GM, Rasmussen SA, Hobbs CA, Canfield MA, Siega-Riz AM, Gallaway MS, Correa A, National Birth Defects Prevention Study (2007) Prepregnancy obesity as a risk factor for structural birth defects. Arch Pediatr Adolesc Med 161:745-750 